Editorial

\title{
From boron exposure in china to lead exposure in Malaysia, paracelsus is still at work
}

\section{Editorial}

Any substance can be toxic at a large enough dose. The corollary is that any substance can be safe at a small enough dose. Paracelsus, the Father of Toxicology, summated that "All things are poison and nothing is without poison; only the dose makes a thing not a poison." This is often condensed to "the dose makes the poison. This idea forms the basis of current risk assessment and management methodologies. In risk assessment, hazards are identified based upon multiple toxicological studies using an escalating dose scheme for different lengths of time by different routes of exposure. Hazards, the lowest dose that caused an adverse effect (i.e., the LOAEL), and the highest dose that did not result in an adverse effect (i.e., the NOAEL) are identified from these studies. The LOAEL or NOAEL from the most sensitive endpoint (identified hazard) is used as the Point of Departure (POD) to derive an exposure limit such as Reference Dose (RFD). An exposure limit such as the RFD is a quantity that even the most susceptible population can be exposed to without reasonably expecting an adverse effect. The RFD is derived by dividing the POD by Uncertainty Factors (sometimes called Safety Factors). The RFD is usually very conservative so that exposure to a larger dose still will not result in harm. Rather, such exposures are identified through routine environmental monitoring to allow for risk management to mitigate the excess exposure before harm occurs. In this issue of MOJT, Duydu and Ustundag derive an RFD for boron, 20.3mg boron/day, based upon effects to the male reproductive system. They note that no adverse effect occurred when workers in China were exposed to $37 \mathrm{mg}$ boron/day. This does not necessarily imply that the RFD is too conservative, but rather that risk management should occur to mitigate exposure. The authors also call for additional epidemiological studies for women exposed to boron which would need to be compared to an RFD based upon a female-relevant endpoint.

The US Environmental Protection Agency (US EPA) derived an RFD of $0.2 \mathrm{mg} / \mathrm{kg}$-bw/day for boron. Using an average human weight
Volume 3 Issue $3-2017$

\author{
Charles Barton \\ DABT,Valspar Corporation, USA
}

Correspondence: Charles Barton, DABT, Global Manager of Toxicology \& Risk Assessment, Valspar Corporation, 2000 Georgetown Drive, Sewickley, PA 15I43, USA, Tel (724) 94038I I,Email dr.charles.barton@gmail.com

Received: July 26, 2017 | Published: July 27, 2017

of $70 \mathrm{~kg}$, the RFD is converted to a daily exposure of $14 \mathrm{mg} /$ day. This is more conservative than the RFD derived by Duydu and Ustundag and allows for earlier application of risk management measures before exposures escalate. Furthermore, the US EPA RfD is derived from the most sensitive endpoint, decreased fetal weight, which is protective of both men and women. Also in this issue of MOJT, Ahmed and colleagues reviewed the data on lead $(\mathrm{Pb})$ levels in drinking water from the Langat River Basin in Malaysia. The authors identify that people may be exposed to doses exceeding various exposure limits. Risk management measures are proposed to mitigate exposures. Paracelsus would be proud that people are protected from harmful doses of chemicals today by application of "the dose makes the poison" in the risk assessment/management paradigm.

\section{Acknowledgements}

None.

\section{Conflict of interest}

The author declares no conflict of interest. 